\title{
EXPOSURE OF THE ISOLATED FROG SKIN TO HIGH POTASSIUM CONCENTRATIONS AT THE INTERNAL SURFACE. I. BIO- ELECTRIC PHENOMENA AND SODIUM TRANSPORT *
}

\author{
By NEAL S. BRICKER, $\dagger$ THOMAS BIBER, $\ddagger$ AND HANS H. USSING
}

(From the Institute of Biological Chemistry, Copenhagen, Denmark)

(Submitted for publication July 23, 1962 ; accepted September 20, 1962)

The skin of the frog represents a prototype of a number of epithelial cell systems which transport sodium ions from one border of the cell to the other. In recent years, a large body of experimental data has accrued relevant to the patterns and mechanism of this process; and on the basis of these observations, Koefoed-Johnsen and Ussing (2) have proposed the following provisional schema, the essential features of which are reproduced in Figure 1.

The transporting epithelial cells are thought to exhibit marked functional polarization at their opposite surfaces. That border facing the outside environment (i.e., the external surface) is highly permeable to sodium ions, but relatively impermeable to potassium ions, whereas the opposing border (i.e., the internal surface) has a high order of potassium permeability, but a low order of permeability to sodium ions. The internal surface is believed to be the site of an active transport mechanism for sodium and possibly for potassium ions. The transcellular movement of sodium ions is conceived of as a two-phase process. Entry into the cells from the environment occurs across the external surface and is characterized by passive transport down an electrochemical potential gradient. Extrusion from the cells requires the "uphill" movement of sodium ions by the active transport system which presumably is located within the structure of the internal plasma membrane.

* Supported by the National Institutes of Health (Grant A-2667) and the Department of the Army, Research and Development Branch (Contract No. DA-49-007-MD772). A preliminary report of these data has been published previously (1).

$\dagger$ Established Investigator, American Heart Association. Present address: Washington University School of Medicine, Saint Louis, Mo.

$¥$ Fellow of the Swiss Foundation for Medical and Biological Fellowships. Present address: University of North Carolina Medical School, Chapel Hill, N. C.
Potassium ions also are shown moving into and out of the cell water; however, these movements are largely confined to the internal surface of the skin. The migration of potassium out of the cell water is depicted as a passive process, which depends upon a favorably oriented electrochemical potential gradient; migration into the cell water is depicted as being active. In accordance with the model, the active entry of potassium ions and the active extrusion of sodium ions depend upon a single membrane carrier system, and it generally is believed that the pump exhibits a $1: 1 \mathrm{Na}: \mathrm{K}$ linkage (2).

In the steady state, this system could allow for the continuing movement of sodium ions from the outside to the inside of the skin and for the regulation of intracellular sodium and potassium content. The rate of passive entry of sodium ions into the cell would be balanced quantitatively by the rate of active transport of sodium out of the cell. Furthermore, if the pump were linked in a $1: 1$ fashion, the rate of active inward movement of potassium ions must remain precisely balanced with the rate of active extrusion of sodium ions. Finally, net rate of potassium diffusion out of the cell would remain equal to the rate of active potassium entry. As long as these four rates remain equivalent there would be no net accession of alkali metal cations within the cell water. Chloride ions may migrate transcellularly passively at a rate equal to the transcellular movement of sodium ions. Thus, the operation of this hypothetical system would not of itself alter the number of osmotically active particles within the cell water and accordingly it should not prejudice the regulation of the constancy of cell water volume.

The Koefoed-Johnsen-Ussing model also is compatible with the bioelectric phenomena that characterize the isolated frog skin under a number of different experimental conditions. The electrical potential gradient across the skin, with 
the internal surface electrically positive to the external surface, is believed to result from the two diffusion potentials: the first due to the passive movement of sodium ions across the external surface, the second to the passive movement of potassium ions across the internal surface. If it were established that a $1: 1$ linkage exists between active transport of sodium and potassium ions, the pump itself would not involve the net transfer of charged particles and hence would be nonelectrogenic. Active transport, therefore, would not contribute to the potential gradient across the skin. However, because the rates of the outward and inward movements of potassium ions across the internal border would be the same, the net transfer of positive charges transcellularly (i.e., from the outside to the inside of the cells) may be equated with the net transcellular movement of sodium ions. It therefore is of considerable interest that the short-circuit current across the isolated frog skin, under most conditions, may be accounted for entirely on the basis of net transcellular sodium migration.

The scientific importance of this ingenious model stems from at least two considerations. First, it provides a provisional basis for interpreting a series of interdependent biologic phenomena; second, as a working hypothesis, it provides stimulus and direction for further investigation. In the present studies, an experimental system has been employed which, within the framework of the model, should preferentially modify one key step in the integrated operation of the isolated frog skin. The concentration of potassium in the solution bathing the internal surface of the skin has been raised to values in excess of the estimated steady state intracellular potassium concentration, thereby attenuating or abolishing the chemical gradient favoring the diffusion of potassium from the inside of the cells into the internal solution. The studies were designed to evaluate the effects of this altered environment on the patterns of sodium transport and on the associated bioelectric phenomena. The data have relevance in two different spheres: 1 ) they imply the existence of active "downhill" (i.e., down an electrochemical potential gradient) transport of sodium; and 2) they indicate the need for additional evaluation of the concept of a $1: 1$ linked sodium : potassium pump.

\section{Epithelial Cell}

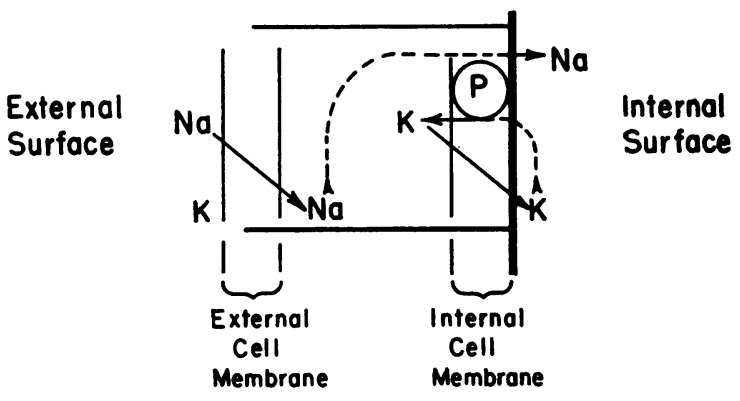

Fig. 1. The KOEFOEd-JOH NSEN-USSING MODEL FOR SODIUM TRANSPORT ACROSS THE EPITHELIAL CELLS OF THE ISOLATED FROG SKIN. The operational details of this model are discussed in the text.

\section{METHODS}

Experiments were performed at room temperature (approximately $22^{\circ} \mathrm{C}$ ) on isolated skins from Rana temporaria, Rana esculenta, Rana arvalis, and Rana pipiens. The animals employed were of both sexes and in the majority of experiments were housed in a $4^{\circ} \mathrm{C}$ cold room for variable periods of time before study; however, representative experiments also were performed on animals maintained at room temperature. No differences in behavior were observed either among the different species or between animals maintained at $4^{\circ}$ and $22^{\circ} \mathrm{C}$.

The animals were double-pithed, and the skins were removed by blunt dissection. After rinsing in standard Ringer's solution for several minutes, the skins were transferred into Lucite chambers so that they divided the chambers symmetrically into two halves. Two types of chambers were employed: in one the volume of solution bathing each side of the skin was 20 to $25 \mathrm{ml}$; in the other the bathing volume was $5 \mathrm{ml}$. In both systems, oxygenation was provided by the constant, or intermittent, bubbling of room air through the bathing solutions. The potential difference across the skin and the shortcircuit current were measured routinely with standard techniques (3) and the agar bridges in contact with the bathing solutions had the same ionic composition as did the bathing solutions.

A total of 75 experiments was performed. In the typical experiment, preliminary observations were obtained with conventional frog sodium Ringer's solution bathing both surfaces of the skin. After steady state conditions had been achieved, control measurements were made for periods varying from 30 to 90 minutes. Thereafter, the conditions were altered according to the design of the particular experiment. One consistent feature of the protocols was the replacement of the sodium Ringer's solution bathing the internal surface of the skin with a solution containing in excess of 110 mmoles per $\mathrm{L}$ of potassium. Further details of the different categories of experiments are included in the text. In most experiments 

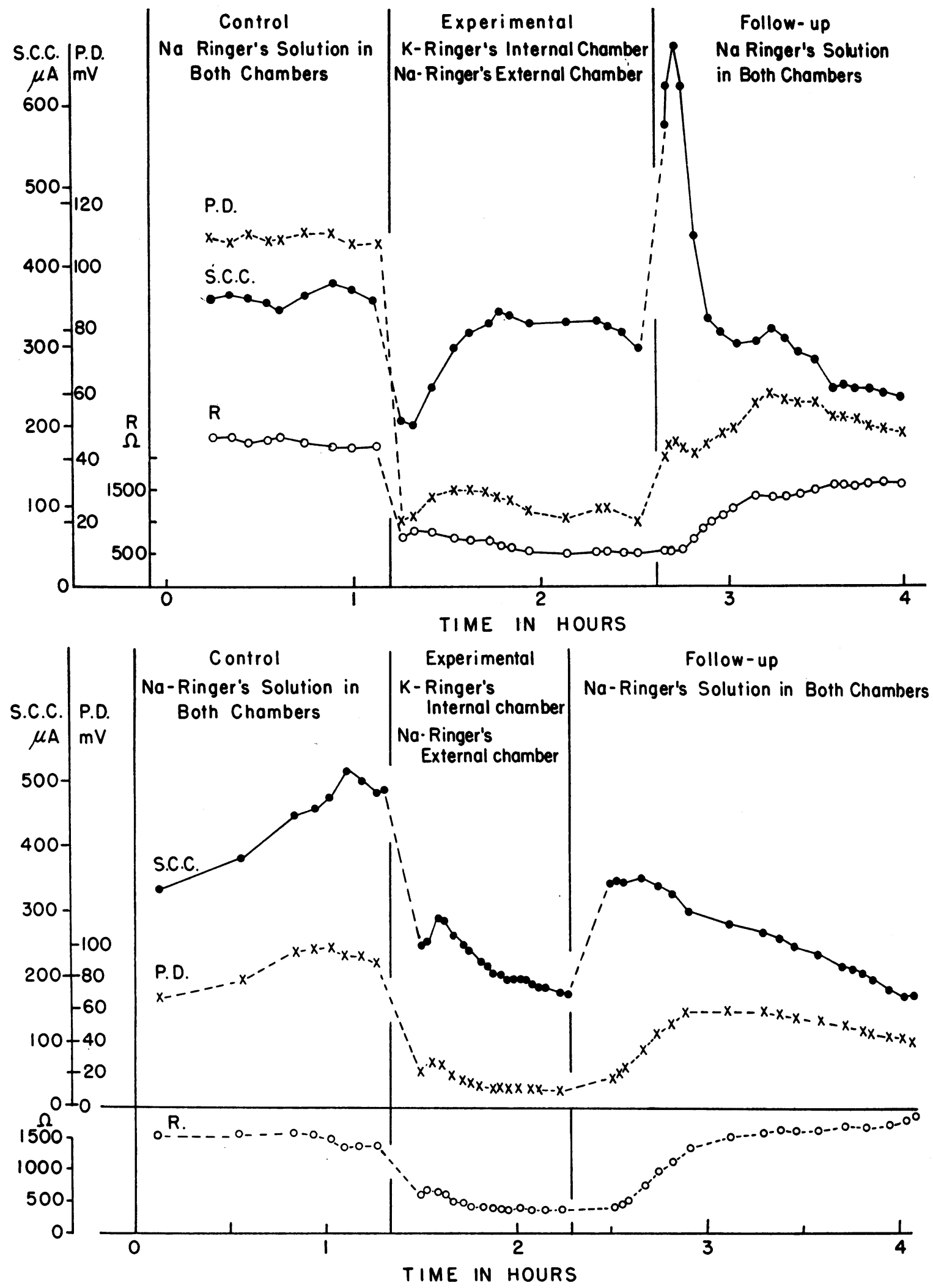

FIG. 2 
sodium Ringer's solution was eventually replaced on both sides of the skin and follow-up measurements were obtained.

The Na-Ringer's solutions had the following composition : $\mathrm{Na}^{+}, 114 \pm 2 \mathrm{mEq}$ per $\mathrm{L}$ : $\mathrm{K}^{+}, 0$ to $2.4 \mathrm{mEq}$ per $\mathrm{L}$; $\mathrm{Ca}^{++}, 1.2 \mathrm{mM}$ per $\mathrm{L} ; \mathrm{Cl}^{-}, 117 \pm 4 \mathrm{mEq}$ per $\mathrm{L}$; $\mathrm{HCO}_{3}^{-}, 2.4$ $\mathrm{mEq}$ per $\mathrm{L}$. The $\mathrm{pH}$ of the Ringer's during aeration was $7.8 \pm 0.2$. The K-Ringer's differed from the Na-Ringer's only in that the concentrations of $\mathrm{K}$ and $\mathrm{Na}$ were reversed.

Flux measurements were made with $\mathrm{Na}^{22}, \mathrm{Na}^{24}$, and $\mathrm{K}^{42}$. When a single isotope was used, samples either were counted in a liquid scintillation counter or were plated, dried, and counted with a thin-window gas-flow counter or a Philips counter with a G.M. tube. When double labeling was performed with two different isotopes used simultaneously, samples were counted either in a liquid phase with a pulse height analyzer, or in a solid phase after plating and drying in aluminum planchets. In the latter instance, the counts were monitored with and without a $1 \mathrm{~mm}$ aluminum filter both immediately after completion of the experiment and again after an interval sufficiently long to allow for well over 99 per cent of the short half-life isotopes of $\mathrm{Na}^{24}$ and $\mathrm{K}^{42}$ to decay. In some of the double-labeling experiments, both methods of counting were used, and a close correspondence was observed between the two sets of data.

In selected experiments, sodium and potassium fluxes also were determined chemically with a Zeiss flame photometer. In these studies, the accession of sodium ions was measured in the internal solution which was initially sodium-free, and the accession of potassium was measured in the external solution which was initially potassium-free.

\section{RESULTS}

Bioelectric measurements. The results of two representative experiments are shown in Figure 2. After control measurements with sodium Ringer's solution bathing both surfaces of the skin, the internal solution was replaced with potassium Ringer's solution. The potassium concentration of this fluid was $114 \mathrm{mM}$ and the sodium concentration $2.4 \mathrm{mM}$ in contrast to the external sodium Ringer's in which the relationships between $\mathrm{Na}$ and $\mathrm{K}$ concentrations were reversed. The $\mathrm{pH}$ and the concentrations of bicarbonate and calcium as well as the total osmolality $(220 \mathrm{mOsm}$ per $\mathrm{kg} \mathrm{H}_{2} \mathrm{O}$ ) of the two solutions were identical. Immediately after the addition of the potassium
Ringer's solution, both the potential difference (P.D.) across the skin and the short-circuit current (S.C.C.) fell precipitously. The former tended to be stabilized at a relatively low level with the peak values averaging $15.6 \mathrm{mv}$ in 21 experiments (range 5.8 to $41 \mathrm{mv}$ ). The S.C.C., on the other hand, exhibited a secondary rise and in eleven experiments became stable at values approximating (Figure 2A) or exceeding the control levels, and in 10 experiments drifted downward slowly (Figure 2B). In most instances, stability of both the P. D. and the S.C.C. persisted for periods as long as several hours in duration. The calculated values for electrical resistance across the skin were markedly diminished during the interval that the skin was in contact with the jotassium Ringer's solution. This change in resistance was an invariable feature of these experiments and occurred within the brief interval (i.e., often less than 1 minute) between addition of the K-Ringer's and the resumption of electrical measurements.

Twenty-five experiments also were performed in which the external sodium Ringer's solution contained no potassium and the internal potassium Ringer's solution contained no sodium. The results were comparable to those shown in Figure 2.

In Figure 3A, data are shown for a typical study with a third type of high potassium solution. In this system, the potassium concentration of the internal solution was increased to $120 \mathrm{mM}$ by adding $\mathrm{KCl}$ to normal Ringer's solution. The total osmolality and the chloride concentration of the latter therefore were increased to approximately twice the values of the external Ringer's solution. The P.D. across the skin decreased markedly and remained between 5 and $10 \mathrm{mv}$ during the period of exposure to the potassium-rich hyperosmotic fluid. The S.C.C. also decreased immediately, but thereafter it arose to a level in excess of the control value. Electrical resistance was markedly depressed. Figure $3 \mathrm{~B}$ depicts an experiment in which the potassium-rich hyperosmotic solution was employed first in the internal chamber (as in Figure 3A) and then in both

Fig. 2, A(Upper) and B(lower). Representative experiments With SOdiUm Ringer's (Na $=114$ Mmoles

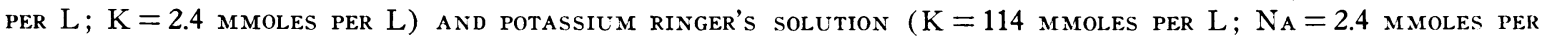
L) in the external and internal chambers, Respectively. Abbreviations: P.D. = potential difference: S.C.C. = short-circuit current: $\mathrm{R}=$ electrical resistance; $\mu \mathrm{a}=$ microamperes per $7 \mathrm{~cm}^{2} ; \mathrm{mv}=$ millivolts ; and $\Omega=$ ohms per 7 $\mathrm{cm}^{2}$. 

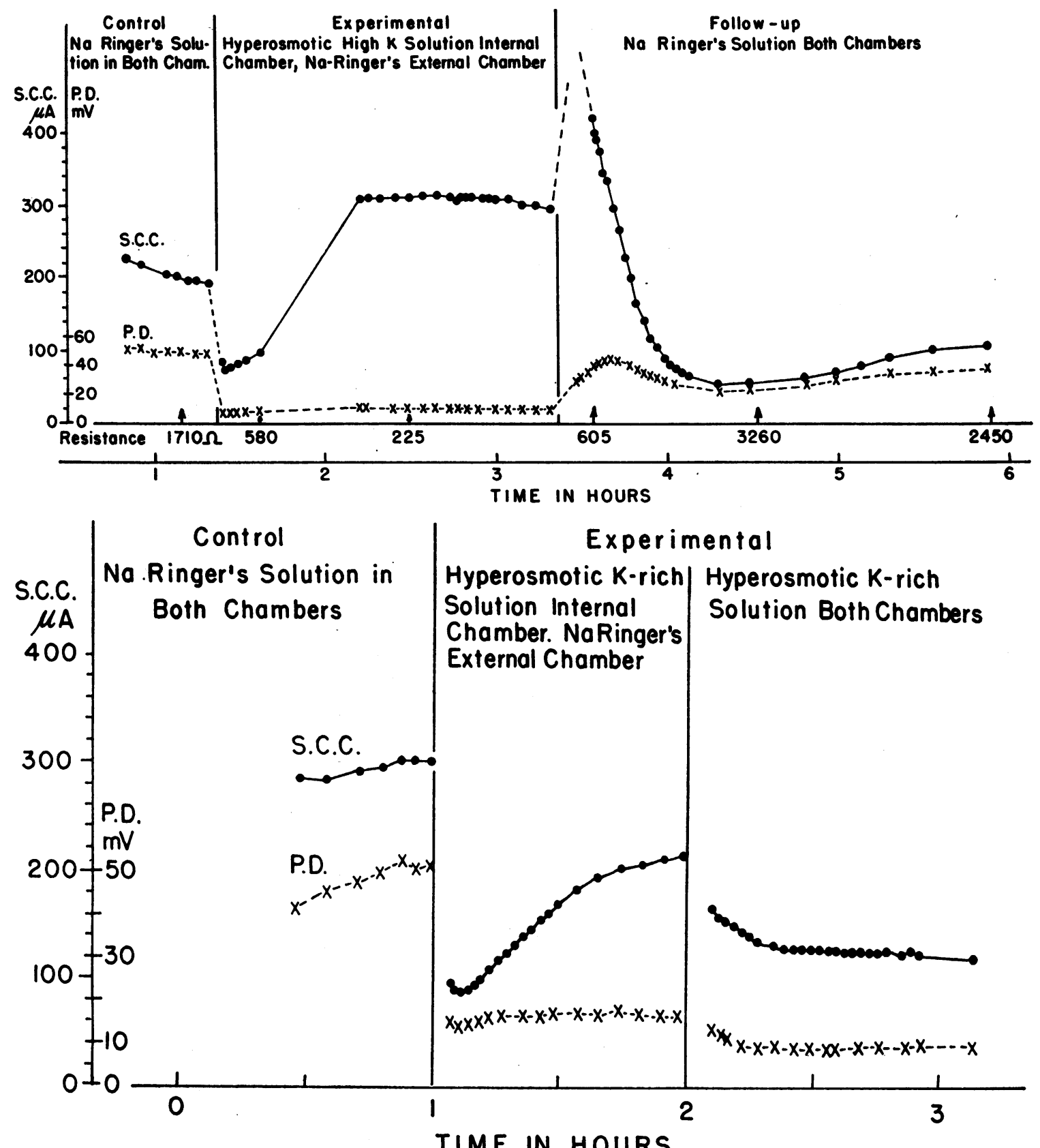

Fig. 3, A (UPper) and B (lower). The effects of potassium-Rich hyperosmotic solutions on the electrical PROPERTIES ON THE ISOLATED FROG SKIN. The potassium concentration of the hyperosmotic solution was $120 \mathrm{mM}$, the sodium concentration $100 \mathrm{mM}$. For composition of the Na-Ringer's solution and definition of terms see Figure 2 and Methods section of text.

chambers. With the symmetrical conditions, which eliminated both the chloride and potassium gradients, P.D. and S.C.C. decreased modestly, and then remained stable.

Reversibility. Continued exposure to the po- tassium-rich internal solution for periods up to several hours in duration rarely resulted in the death of the skins. Representative patterns of behavior after replacement of Na-Ringer's solution in both chambers are included in Figures 2A, 2B, 


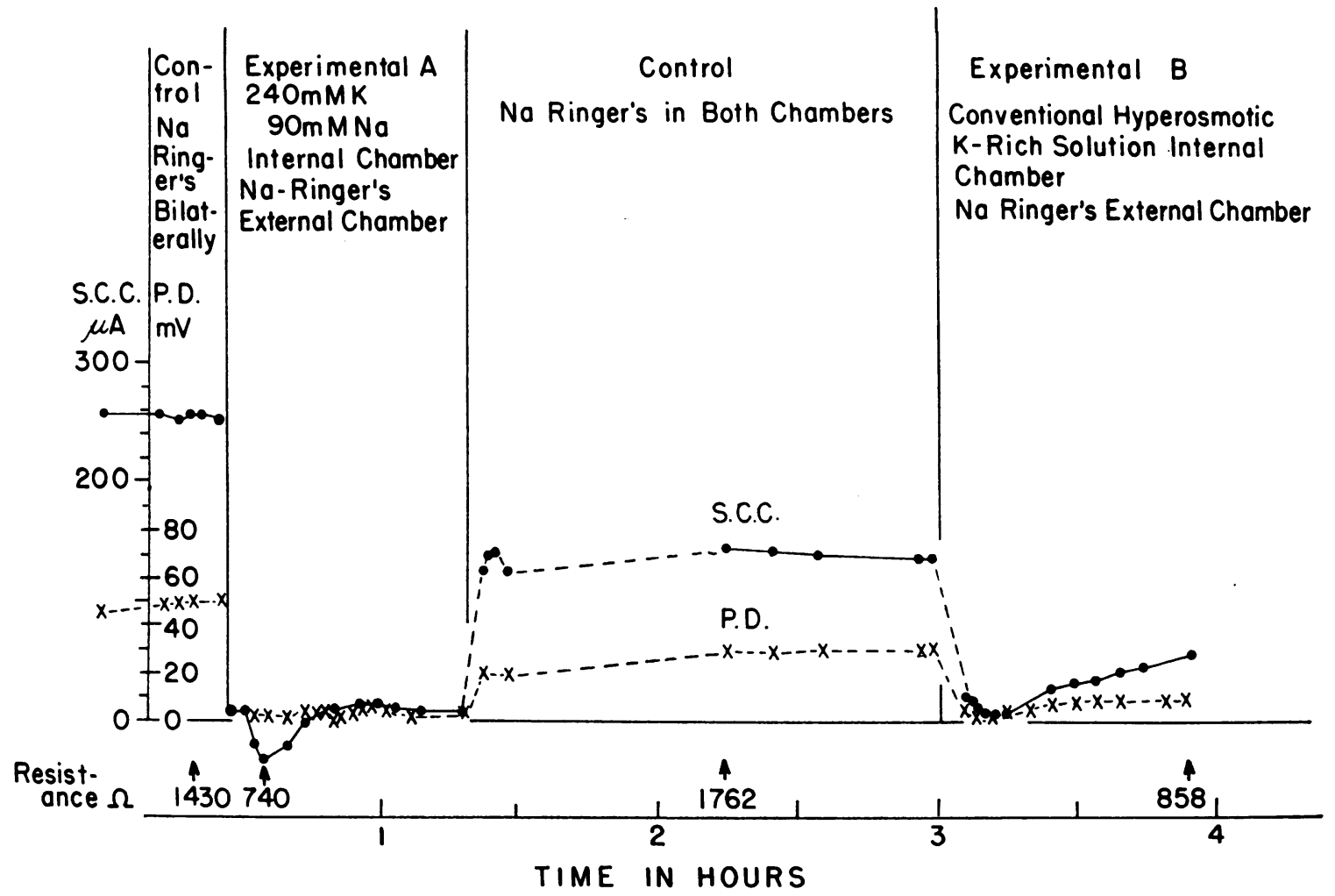

Fig. 4. The influence of Hyperosmotic K-RICH RINGER'S SOlUtion in the internal Chamber on the eleCtrical VIABILITY OF THE ISOLATED FROG SKIN.

and 3A. With both the sodium-poor and sodiumfree potassium Ringer's, the P.D. increased appreciably in the follow-up periods. The S.C.C. exhibited an initial spike which often was of striking proportions (Figure 2A), and thereafter positive values persisted for periods as long as 36 hours. The behavior after exposure to the hyperosmotic potassium-rich solution was more variable, but in all instances the electrical integrity of the preparations persisted (Figure 3A). Under

TABLE I

Bidirectional Na fluxes and $\mathrm{K}$ efflux across isolated frog skin*

\begin{tabular}{|c|c|c|c|c|c|c|c|}
\hline Conditions & Time & $\underset{\text { influx }}{\stackrel{\mathrm{Na}}{2}}$ & $\begin{array}{l}\stackrel{\text { Na }}{\text { efflux }} \\
\text { efla }\end{array}$ & $\begin{array}{l}\text { Net } \\
\text { Na } \\
\text { flux }\end{array}$ & $\underset{\text { efflux }}{\mathrm{K}}$ & $\begin{array}{l}\text { Net Na flux } \\
\text { minus } K \\
\text { efflux }\end{array}$ & $\begin{array}{c}\text { Short-circuit } \\
\text { current } \\
\text { integrated }\end{array}$ \\
\hline & $\min$ & $\mu a$ & $\mu a$ & $\mu a$ & $\mu a$ & $\mu a$ & $\mu a$ \\
\hline $\begin{array}{l}\text { Control } \\
\text { Na-Ringer's, } \\
\text { both chambers }\end{array}$ & 71 & 419 & 23 & 396 & 4 & 392 & 377 \\
\hline $\begin{array}{l}\text { Experimental } \\
\text { K-Ringer's, }\end{array}$ & 40 & 343 & 33 & 310 & 101 & 209 & 225 \\
\hline $\begin{array}{l}\text { internal chamber } \\
\text { Na-Ringer's (K-free) }\end{array}$ & 39 & 358 & 4 & 354 & 128 & 226 & 242 \\
\hline external chamber & 38 & 368 & 4 & 364 & 194 & 170 & 192 \\
\hline $\begin{array}{l}\text { Follow-up } \\
\text { Na-Ringer's, }\end{array}$ & 33 & 423 & 38 & 385 & 91 & 294 & 283 \\
\hline both chambers & 30 & 287 & 41 & 246 & 21 & 225 & 229 \\
\hline
\end{tabular}

* Bidirectional $\mathrm{Na}$ fluxes were measured with $\mathrm{Na}^{22}$ and $\mathrm{Na}^{24}$; net $\mathrm{Na}$ flux $=\mathrm{Na}$ influx $-\mathrm{Na}$ efflux; $\mathrm{K}$ efflux was measured chemically and represents the accession of potassium in the external solution. 
each of these experimental conditions, the electrical resistance increased appreciably during follow-up measurements. In Figure 4, additional observations relevant to the reversibility phenomenon are shown. The potassium-rich solution employed in the internal chambers in this study had a concentration of $240 \mathrm{mM}$ of potassium and an osmolality of three times that of the sodium Ringer's solution in the external chamber. After replacement of new sodium Ringer's in both chambers, electrical recovery of the skin was observed. This preparation was then maintained in sodium Ringer's for approximately 2 hours, and thereafter the conventional potassium-rich hyperosmotic solution, containing 120 mmoles per $\mathrm{L}$ of potassium and an osmolality twice that of normal Ringer's was introduced into the inside chamber. The response was qualitatively similar to that shown in Figure 3 for an intact skin.

Relationship between the short-circuit current and sodium transport. In Table I, values for the S.C.C. are compared with the concurrent values for bidirectional sodium flux measurements. Sodium influx (from external to internal solutions) was measured with $\mathrm{Na}^{22}$ and sodium efflux with $\mathrm{Na}^{24}$. During the control period, net sodium flux (i.e., influx minus efflux) corresponded relatively closely to the S.C.C. when both parameters were expressed in $\mu$ a. However, during three consecutive periods of approximately 40 minutes each, with K-Ringer's bathing the internal surface of the skin, the net sodium flux exceeded the S.C.C. by as much as 90 per cent. These results, therefore, represent one of the few recorded situations wherein these two parameters are grossly divergent. After replacement of Na-Ringer's in both chambers, the differences between net sodium flux and S.C.C. diminished, and during the second follow-up period, the degree of correspondence was equivalent to that observed in the control period.

Data for transcellular potassium efflux (from internal to external solutions) also are included in Table I. During the control period, the value was insignificant; however, during the three periods with the K-Ringer's solution in the internal chamber, potassium efflux increased progressively. When the values for potassium efflux were subtracted from those for net sodium flux, the derived values were found to approximate the S.C.C. more closely. In fact, the values obtained from the ionic fluxes averaged approximately 10 per cent less than those for the integrated S.C.C. In the follow-up measurements, net potassium efflux diminished towards the control level, and in the final period of observation, the value obtained from flux measurements was virtually identical with the measured S.C.C.

Characteristics of sodium transport. In the studies involving substitution of K-Ringer's for Na-Ringer's in the internal chamber, the transcellular electrochemical gradient for sodium ions (from outside to inside) was "downhill." Thus the net flux of sodium could be entirely passive. In order to determine whether active sodium transport continued under these conditions, several experimental procedures have been employed. In Table II the results of five experiments are shown during which bidirectional sodium fluxes were measured with $\mathrm{Na}^{22}$ and $\mathrm{Na}^{24}$. The ratios of $\mathrm{Na}$ influx to $\mathrm{Na}$ efflux are compared with the corresponding ratios for $\mathrm{Na}$ concentration in the external solution to $\mathrm{Na}$ concentration in the internal solution. According to the flux equation formulated by Ussing and Zerahn (3), the flux ratios should equal the concentration ratios if the movements of sodium are due to passive transport alone under conditions wherein the spontaneous P.D. is eliminated by short-circuiting. In each of the double-labeling experiments, however, the flux ratios exceeded the concentration ratios during the period of exposure to potassium Ringer's solution.

The effects of strophanthin on sodium transport during exposure to potassium Ringer's solution are shown in experiments 2 through 5 in Table II. In each instance, sodium influx decreased after addition of $1.4 \times 10^{-4} \mathrm{M}$ strophanthin to the internal solution. No consistent or marked change occurred in sodium efflux. However, in each instance, the flux ratios approximated the concentration ratios. In association with the addition of strophanthin, the P.D. and S.C.C. values fell precipitously and often became negative.

In Figure 5, the influence of potassium cyanide on the P.D. and S.C.C. is shown. After the internal surface of the skin had been in contact with K-Ringer's solution for approximately 1 hour, $\mathrm{KCN}$ was added to the external solution in a final concentration of $1 \times 10^{-2}$ M. A rapid 
TABLE II

Flux ratios during exposure of the internal surface of frog skin to potassium Ringer's solution and the effects of $1.4 \times 10^{-4} M$ strophanthin on these ratios*

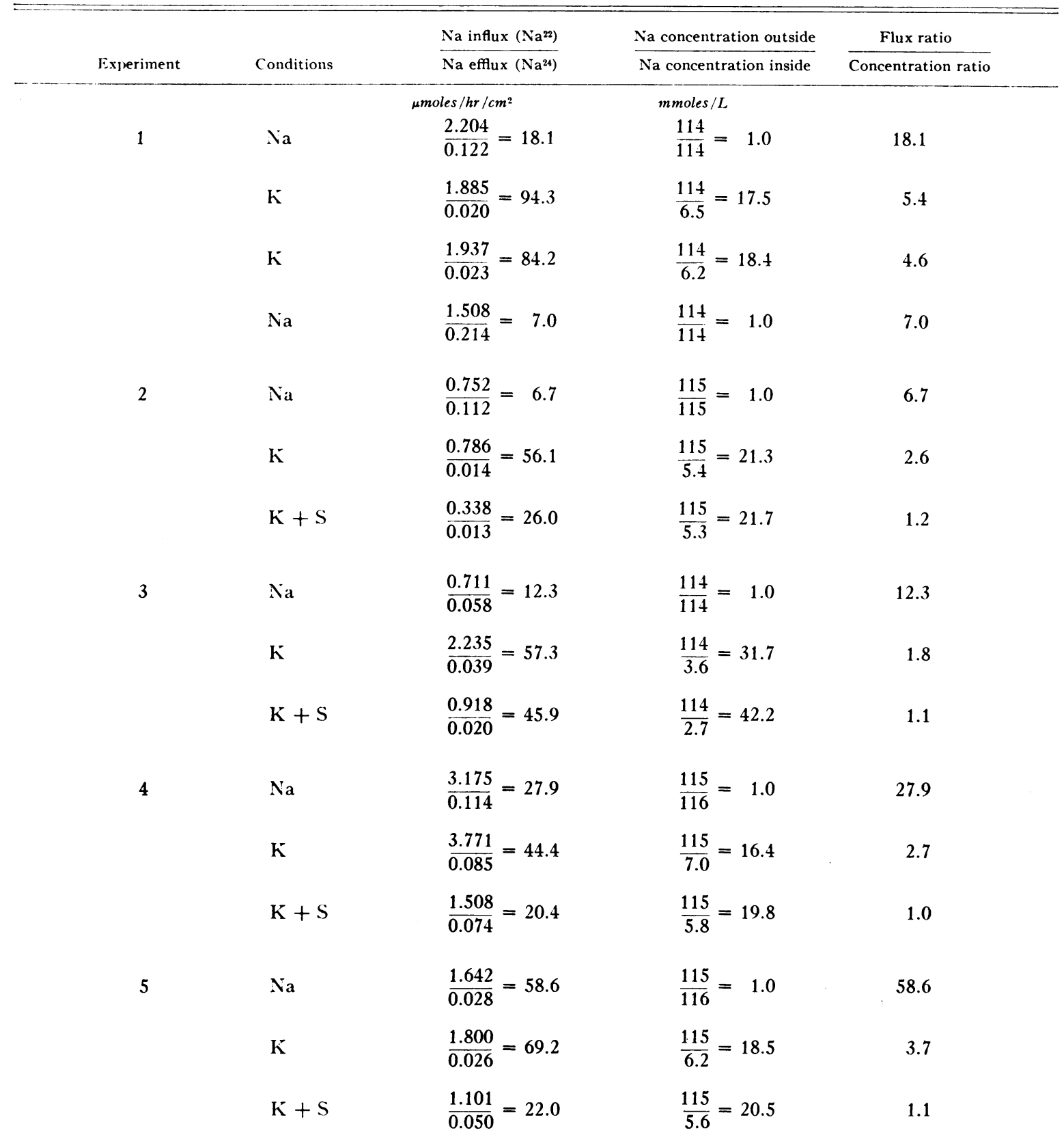

* $\mathrm{Na}=$ sodium Ringer's solution, $\mathrm{K}=$ potassium Ringer's solution, $\mathrm{S}=$ strophanthin. A thirty-minute period of equilibration was allowed between addition of $\mathrm{K}$-Ringer's (containing $\mathrm{Na}^{24}$ ) to the internal chamber and initiation of flux measurements. The strophanthin was added to the internal solution in a final concentration of $1.4 \times 10^{-4} \mathrm{M}$. After the addition of strophanthin, the P.D. (potential difference) and S.C.C. (short-circuit current) fell precipitously and of ten assumed negative values. Experiments 1 and 2 were performed on Rana temporaria; experiment 3 on Rana esculenta; and experiments 4 and 5 on Rana arvalis. Because of the considerable $\mathrm{Na}$ influx into the (5 ml) internal chamber, the arithmetic mean of initial and final chemical concentrations of $\mathrm{Na}$ in the internal solution was used in these calculations. In calculating $\mathrm{Na}$ efflux, the specific activity of $\mathrm{Na}^{24}$ in the internal solution was based on these mean values. The chemical concentration of $\mathrm{Na}$ in the external Na-Ringer's was sufficiently high, so that it was not necessary to make corresponding corrections for $\mathrm{Na}$ concentrations and specific activity of $\mathrm{Na}^{22}$ in the external solution. 


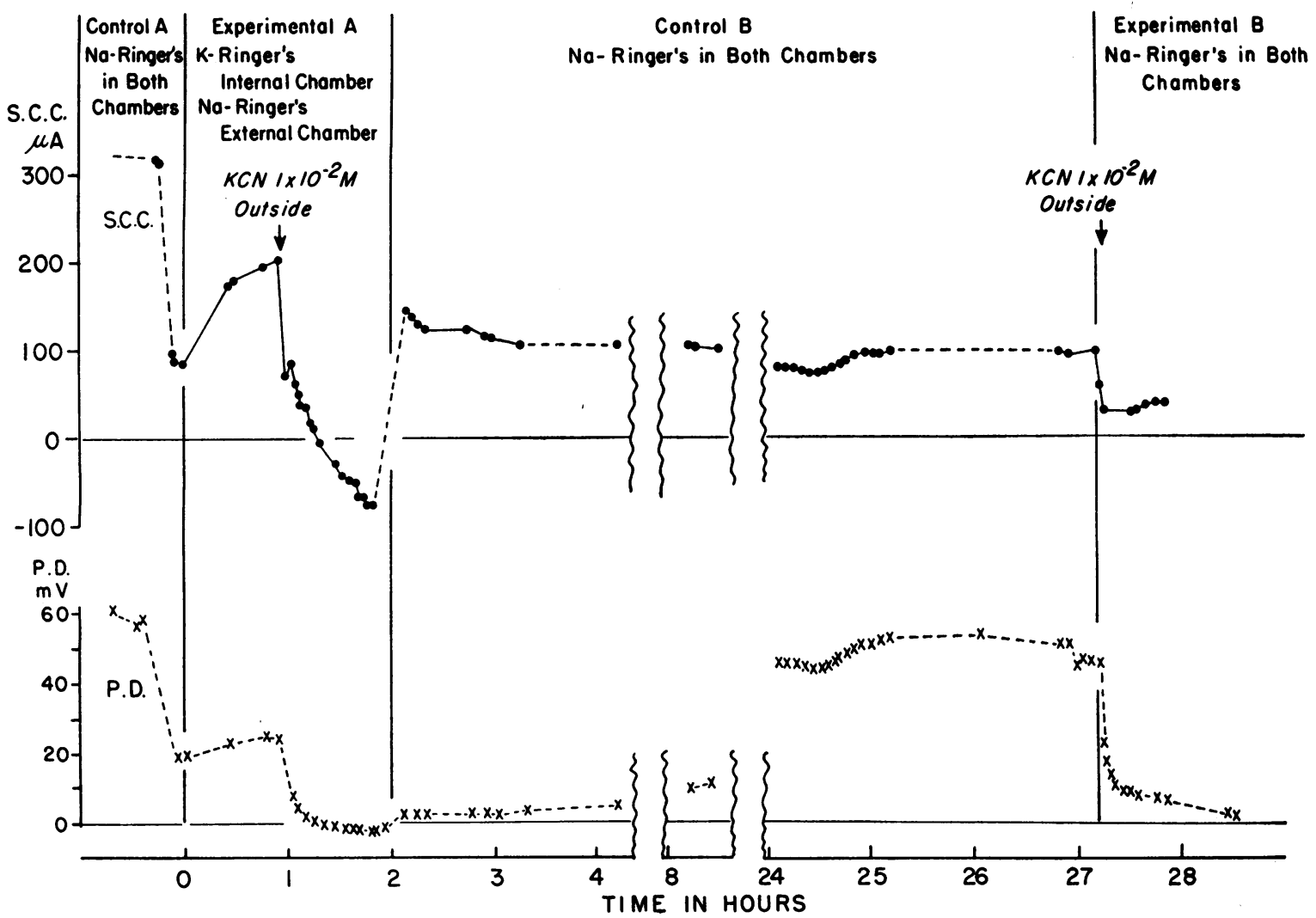

Fig. 5. THE EFFECTS OF $1 \times 10^{-2} \mathrm{M}$ KCN ON THE POTENTIAL DIFFERENCE AND SHORT-CirCUIT CURRENT With POTASSIUM RINGER'S SOLUTION IN THE INTERNAL CHAMBER.

and progressive decrease in both the potential and the current followed, and eventually both values became negative. That this response was not simply a function of a dead preparation is suggested by the recovery noted after the skin was washed and Na-Ringer's replaced in both chambers. The viability of this skin was still mani-

TABLE III

Effect of $K C N$ on sodium influx during exposure to K-Ringer's*

\begin{tabular}{clc}
\hline Time & \multicolumn{1}{c}{ Conditions } & \multicolumn{1}{c}{$\mathrm{Na}^{22}$ influx } \\
\hline $\begin{array}{c}\text { min } \\
45.5\end{array}$ & $\begin{array}{l}\text { Na-Ringer's, both } \\
\text { chambers }\end{array}$ & $\begin{array}{c}\mu \text { moles } / \mathrm{hr} / \mathrm{cm}^{2} \\
0.67\end{array}$ \\
32.5 & $\begin{array}{l}\text { K-Ringer's, internal } \\
\text { chambers; Na Ringer's, }\end{array}$ & 0.66 \\
30.0 & $\begin{array}{l}\text { external chamber } \\
36.5\end{array}$ & 1.06 \\
20.0 & $\begin{array}{l}\text { KCN added to internal } \\
\text { solution (1 X 10 }\end{array}$ & 1.54 \\
21.5 & & 1.29 \\
\hline
\end{tabular}

* The measurements were made continously without allowing time for equilibration. Rana temporaria were used. fested 26 hours after the initial application of $\mathrm{KCN}$; and at this time, with Na-Ringer's in both chambers, retreatment of the skin with $\mathrm{KCN}$ resulted in a prompt fall in P.D. and S.C.C., although under these conditions the values remained positive.

Table III depicts the effects on $\mathrm{Na}^{22}$ influx of the addition of $\mathrm{KCN}$ to the Na-Ringer's solution in the external chamber. Sodium influx averaged $0.67 \mu$ mole per $\mathrm{cm}^{2}$ per hour during the two control periods and $0.88 \mu$ mole per $\mathrm{cm}^{2}$ per hour during the two consecutive periods of exposure to K-Ringer's solution in the internal chamber. With the addition of $\mathrm{KCN}$ in a final concentration of $1 \times$ $10^{-3} \mathrm{M}$, the values for net sodium influx increased to $1.32 \mu$ moles per $\mathrm{cm}^{2}$ per hour. This increase in unidirectional sodium flux occurred despite the fact that the values for P.D. and S.C.C. fell rapidly towards zero and then became negative. In this experiment, the internal solution was $\mathrm{Na-}$ free; hence, the values for sodium influx may be equated with net flux of sodium. The fact that the 
current was negative in the presence of high rates of sodium migration suggests that potassium efflux was markedly accelerated by the application of cyanide across what was presumably a dead skin. ${ }^{1}$

Two other metabolic inhibitors have been employed in an attempt to characterize the nature of the transcellular sodium migration during exposure to high potassium solutions. Dinitrophenol in concentrations of $1 \times 10^{-4} \mathrm{M}$ did not evoke any consistent changes in the P.D. or the S.C.C. values. However, lowering of the temperature of the bathing solutions from $22^{\circ} \mathrm{C}$ to $4^{\circ} \mathrm{C}$ was attended by a decrease in P.D. and S.C.C. of approximately 50 per cent. The values then returned towards the control level as the temperature was raised.

\section{DISCUSSION}

In the present report, observations are described on the bioelectric phenomena and the patterns of sodium transport of the isolated frog skin under conditions in which the internal surface was bathed with various types of high potassium solutions. In the majority of studies, the concentration of potassium varied from 114 to $120 \mathrm{mM}$. When potassium Ringer's solution $(\mathrm{K}=114$ mmoles per L) was used in the internal chamber, with sodium Ringer's in the external chamber, the spontaneous P.D. across the skin decreased abruptly, but thereafter values tended to stabilize generally between 5 and $20 \mathrm{mv}$ for periods up to several hours in duration. The S.C.C. also diminished immediately after addition of the K-Ringer's, but these values also increased and tended to reach a plateau at levels varying from 50 to 150 per cent of the control values. Finally, the calculated electrical resistance of the skin decreased abruptly and remained low throughout the observations. $^{2}$

In association with the changes in the electrical properties of the skin, the transcellular movement of sodium ions from the external to the internal

\footnotetext{
1 Attempts to restore the electrical integrity of this preparation by washing it repeatedly and replacing it in fresh $\mathrm{Na}$-Ringer's were unsuccessful.

2 In association with the decrease in resistance, the membranes were unresponsive to mammalian vasopressin (Pitressin).
}

solutions continued, generally at a rate comparable to that observed during the control periods. The nature of this sodium influx and its relationship to the S.C.C. have been subjects of particular interest. In most experiments the external $\mathrm{Na}$ concentration was $114 \mathrm{mM}$ while the concentration of $\mathrm{Na}$ in the internal K-Ringer's solution ranged from 0 to $6 \mathrm{mM}$. In the absence of a spontaneous P.D. across the skin (i.e., under conditions of complete short-circuiting), the electrochemical potential gradient for $\mathrm{Na}$ was "downhill," and the next flux of this ion therefore might be explicable entirely on the basis of passive transport. However, several lines of evidence suggest that active sodium transport continued. When the bidirectional movements of sodium were measured simultaneously, the flux ratios were consistently greater than could be accounted for on the basis of passive transport. Furthermore, when strophanthin was added to the potassium Ringer's solution, not only did sodium influx rates diminish, but the flux ratios closely approximated the sodium concentration ratios. Finally, the negative values for P.D. and S.C.C., which attended the addition of $\mathrm{KCN}$, and the drop and subsequent rise in these values with lowering and elevation of temperature also are consistent with the continued operation of an active sodium transport mechanism. These observations, therefore, are believed to support the conclusion that active sodium transport persisted despite the altered environmental conditions of the internal surface of the skin. Hence, the data would appear to document the phenomenon of active "downhill" sodium transport.

The data obtained with sodium and potassium Ringer's solutions may have implications regarding another aspect of active sodium transport. According to the Koefoed-Johnsen-Ussing model, the sodium pump is not electrogenic. If a skin with Ringer's solution on both sides is shortcircuited, the current is presumed to cross the internal boundary of the epithelial cells in the form of potassium ions diffusing down a concentration gradient. In the experiments presented above, however, the electrochemical potential gradient for potassium (from cell interior to internal solution) must have been either greatly reduced or reversed. Hence, the origin of the S.C.C. 
becomes a problem of considerable theoretical interest.

It is not possible on the basis of the available data to construct a complete balance sheet for the movement of all ionic species present. It is possible, however to derive semi-quantitative estimates of the major sources of the electric current. Part of the current may be attributed to the passive diffusion of sodium ions. If it is assumed that this passive diffusion obeys the flux ratio equation, the magnitude of passive influx may be estimated as the $\mathrm{N}$ a efflux times the ratio of $\mathrm{Na}$ concentration in external solution to $\mathrm{Na}$ concentration in internal solution (see Table II). Calculations based on this formulation suggest that between one-fourth and one-half of the total sodium influx is passive. However, this sodium diffusion is roughly balanced by the simultaneous outward diffusion of potassium ions; hence it still is necessary to account for most of the observed S.C.C.

Attention may next be directed to the possibility that potassium diffusion continued to contribute to the S.C.C. despite the fact that the potassium concentrations of the internal solutions typically exceeded $110 \mathrm{mEq}$ per $\mathrm{L}$. The answer to this would depend upon whether or not the normal potassium gradient from cell water to internal solution was abolished. It is conceivable that the potassium concentration of the epithelial cells of normal skin may be higher than $100 \mathrm{mEq}$ per L. Thus much of the intracellular anion consists of proteins and phosphate esters which average more than one negative charge per ion, while the predominant cellular cation potassium and the intracellular sodium ions are monovalent. Hence. osmotic equilibrium between the cell water and the internal solution requires that the sum of cellular potassium and sodium ions be higher than the corresponding sum of these ions in the Ringer's solution. On the other hand, it has been observed that the epithelial cells of skins exposed to the K-Ringer's solutions at their internal surfaces undergo considerable swelling, with the thickness of individual cells often increasing by as much as 200 per cent within two hours. ${ }^{3}$ In these swollen cells, monovalent chloride ions must constitute the great majority of intracellular anion.

\footnotetext{
${ }^{3}$ These observations will be reported in detail separately.
}

The concentration of potassium plus sodium required for osmotic equilibrium therefore need not be much higher than the corresponding sum of these two cations in the internal bathing solution. Moreover, analyses of skins which have been in contact with potassium Ringer's in the internal chamber and sodium Ringer's in the external chamber for one to two hours indicate that a large fraction of the cellular cation is comprised of sodium (i.e., the estimated sodium concentration of the water phase of the epithelium may be as high as $82 \mathrm{mEq}$ per L). Although some uncertainty arises from the fact that the sodium values are calculated for all layers of the epithelium, whereas the critical potassium gradient exists across the internal plasma membrane at the innermost layer of epithelial cells, these data are felt to support the view that the chemical gradient for potassium from cell water into internal medium either was abolished or reversed. Although the electrical potential gradient across the internal border of the epithelial cells was not measured, the skins were maintained in a short-circuited state, and Frazier recently has shown that in the chronically shortcircuited isolated toad bladder, the interior of the epithelial cells is electrically negative to both bathing solutions (4). If a similar situation existed under the present experimental conditions, the combined electrochemical gradient across the internal border could have supported a reversal of the normal direction of net potassium diffusion. Moreover, even if it is assumed that the cellular potential was zero in these studies, it is very difficult to envision any appreciable electrochemical gradient which would support potassium migration from cell water into internal solution. Thus, it is unlikely that the S.C.C. can be accounted for on the basis of a potassium diffusion current.

There are other sources of current which must be considered. The movement of chloride ions from the internal to the external boundaries of the epithelial cells could generate a S.C.C. For example, there is evidence that the mucus-secreting glands of the isolated frog skin, when stimulated by adrenaline, will actively transport chloride ions in an outward direction $(5,6)$. In the short-circuited state, adrenaline-stimulated active chloride transport may account for a sustained current of as much as $19 \mu \mathrm{a}$ per $\mathrm{cm}^{2}$. At the present time 
it is not known whether exposure of the frog skin to high internal potassium solutions activates mucus gland chloride secretion; however, even the highest chloricle currents observed in adrenalinestimulated skins cannot account for all of the current in the present experiments.

An electric current might also be generated if sodium ions diffused into the cells from the external solution and chloride ions simultaneously diffused into the cells in equivalent amounts from the internal solutions with the subsequent trapping of $\mathrm{NaCl}$ within the cell water. As already mentioned, the cells swell rapidly with the K-Ringer's solution in the internal chamber. This swelling, however, can be related only in part to the uptake of potassium chloride from the internal solution. The high sodium content in the swollen epithelia indicates that more sodium diffuses into the cells than is transported out. If electroneutrality in the cell water were achieved by a corresponding uptake of chloride ions from the internal solution (this is possible because the skin is short-circuited), the net effect in electric terms would be a positive current in an inward direction. The maximal value for this current as estimated from the sodium uptake in the epithelia would be 35 $\mu$ a per $\mathrm{cm}^{2}$ over a one-hour period. This would require, however, that no chloride enter the cells from the external solution, and the true value for a "swelling current" would probably be considerably less than $35 \mu \mathrm{a}$.

Thus, the possibility exists that the active transport of sodium ions per se accounted for net charge transfer across the internal border of the epithelial cells, and hence that active sodium transport contributed to the S.C.C. This in turn would indicate that the active sodium transport mechanism was an electrogenic process, and hence that a tight $1: 1 \mathrm{Na}: \mathrm{K}$ coupling did not exist under the experimental conditions employed.

\section{SUM MARY}

In the present studies, the internal surface of the short-circuited isolated frog skin was exposed to potassium concentrations varying from 110 to 120 $\mathrm{mM}$. Conventional frog Na-Ringer's solution generally was maintained in contact with the external surface. Potential difference (P.D.) short-circuit current (S.C.C.), and electrical resistance all decreased immediately upon exposure to the high potassium solutions. P.D. typically became stable at 20 per cent or less of the control values, electrical resistance remained low, but S.C.C. rose, and in most instances reached levels varying from 50 to 150 per cent of control values. When isosmotic Na- and K-Ringer's were used on opposite surfaces of the skin. net sodium influx across the skin not only persisted, but values appreciably exceeded S.C.C. The discrepancy between these two parameters was related largely to the transcellular efflux of potassium ions. Because sodium transport occurred down a steep electrochemical gradient, the process could have been entirely passive. However, during complete short-circuiting, the ratio of the unidirectional sodium fluxes (using $\mathrm{Na}^{22}$ and $\mathrm{Na}^{24}$ ) consistently exceeded the ratio of sodium concentrations in the bathing solutions. Furthermore, after addition of strophanthin $\left(1.4 \times 10^{-4} \mathrm{M}\right)$, flux ratios promptly fell to approximate concentration ratios. These data are believed to demonstrate the phenomenon of "downhill" active transport. The cumulative observations also may have a bearing on another aspect of active sodium transport. On the basis of persistence of high values for S.C.C. in the face of a possible reversal in the normal direction of net potassium diffusion across the internal border of the epithelial cells. the possibility has been considered that the active transport of sodium may have been an electrogenic process.

\section{REFERENCES}

1. Bricker, N. S., and Biber, T. Active "downhill" sodium transport across the isolated frog skin. J. clin. Invest. 1962, 41, 1348.

2. Koefoed-Johnsen, V., and Ussing, H. H. The nature of the frog skin potential. Acta physiol. scand. 1958, 42, 298.

3. Ussing, H. H., and Zerahn, K. Active transport of sodium as the source of electric current in the short-circuited isolated frog skin. Acta physiol. scand. 1951, 23, 110.

4. Frazier, H. S. The electrical potential profile of the isolated toad bladder. J. gen. Physiol. 1962, 45, 515.

5. Koefoed-Johnsen, V., Levi, H., and Ussing, H. H. The mode of passage of chloride ions through the isolated frog skin. Acta physiol. scand. 1952, 25. 150.

6. Koefoed-Johnsen, V., Ussing, H. H., and Zerahn, K. The origin of the short-circuit current in the adrenaline stimulated frog skin. Acta physiol. scand. 1952, 27, 38. 